\title{
Redescription of Harpactea christodeltshevi Bayram, Kunt \& Yağmur, 2009 (Araneae, Dysderidae) from Turkey
}

Recep Sulhi ÖZKÜTÜK1*, Ersen Aydın YAĞMUR², Kadir Boğaç KUNT1,3, Nergis KARADUMAN1,

\author{
${ }^{1}$ Department of Biology, Faculty of Science, Eskişehir Technical University, TR- 26470 Eskişehir, Turkey \\ ${ }^{2}$ Alaşehir Vocational School, Celal Bayar University, TR-45600 Alaşehir, Manisa, Turkey \\ ${ }^{3}$ Cyprus Wildlife Research Institute, Taşkent, Kyrenia, Cyprus \\ ORCID ID: Recep Sulhi ÖZKÜTÜK: https:// orcid.org/0000-0001-5030-3008; Ersen Aydın YAGMUR: https:// orcid.org/0000-0002-0396-3975; \\ Kadir Boğaç KUNT: https:// orcid.org/0000-0003-3137-5510; Nergis KARADUMAN: https:/ /orcid.org/0000-0001-7175-5353
}

\begin{tabular}{llll}
\hline Received: 04.09.2019 Issue published: 20.12 .2019 & Published online: $20.12 .2019 \quad 01.10 .2019$ & Accepted
\end{tabular}

Abstract: In this study, Harpactea christodeltshevi from the southeast Anatolia region of Turkey, is re-described. Some of the information about the body features of females which has not been known to date is given and pictures of female copulatory organ is also presented. H. christodeltshevi is in the rubicunda (D) group because of the structural features of the body and reproductive organs and its female copulatory organ is unique because of the spherical structure in the tip of the anterior spermatheca and sclerotized ring just under it. Additionally, it is debated that the species saved recently in Gaziantep, Turkey and recorded as Stalagtia hercegovinensis is actually H. christodeltshevi.

Keywords: Anatolia, Southeast Anatolia, Harpacteinae, spider.

\section{Türkiye'den Bilinen Harpactea christodeltshevi Bayram, Kunt \& Yağmur, 2009 (Araneae, Dysderidae)'nin yeniden betimlenmesi}

Öz: Bu çalışmada Türkiye'nin Güneydoğu Anadolu bölgesinden bilinen Harpactea christodeltshevi türünün yeniden betimlenmesi yapılmıştır. Türün daha önceden bilinmeyen dişisine ait bazı vücut özelliklerine dair bilgiler verilmiş ve ayrıca dişi üreme organının fotoğrafları da sunulmuştur. H. christodeltshevi, hem vücut hem de üreme organlarının yapısal özelliklerinden dolayı rubicunda (D) tür grubuna dâhil olup türün dişi üreme organı, ön spermatekasının ucunda yer alan küresel yapıya sahip ve hemen onun altında bulunan sklerotize yüzük dolayısıyla eşsizdir. Bunların yanı sıra, yakın geçmişte Türkiye'nin Gaziantep ilinde Stalagtia hercegovinensis olarak kaydedilen türün esasında H. christodeltshevi olduğu da tartışılmıştır.

Anahtar kelimeler: Anadolu, Güneydoğu Anadolu, Harpacteinae, örümcek.

\section{Giriş}

Örümceklerin Dysderidae familyasına bağlı Harpacteinae alt familyasının yaşayan 181 tür (WSC, 2019) ile en kalabalık cinsi olan Harpactea, Türkiye'de 29 tür ile temsil edilmektedir (Danışman, Kunt, \& Özkütük, 2019). Bu türlerin büyük çoğunluğunun dağılımları tip yerleri ile sınırlı iken bazıları nispeten daha geniş dağılım göstermektedirler. Örneğin bunlardan $H$. babori, Türkiye Trakya'sının doğu sahil şeridi, Yıldız Dağlarının geneli ve İstanbul'da; $H$. sturanyi ise Türkiye'nin batı iç ve sahil kesimlerinde dağılım göstermektedir (Kunt, 2019).

2000'li yılların sonunda, Bayram, Kunt ve Yağmur (2009) tarafından Adıyaman'ın Gerger ilçesinin $2 \mathrm{~km}$ batısında bulunan $H$. christodeltshevi, Türk araştırmacılar tarafından erkek eşey üzerinden betimlenen ilk Harpactea türüdür.

Bu kısa makalenin amacı $H$. christodeltshevi türünü yeniden betimlemektir. Makale içerisinde türün erkek ve dişi bireylere ait üreme organlarının fotoğrafları verilecek ve ayrica ilk betimleme makalesinde yapılan bazı teknik yanlışlıklar düzeltilecektir.

\section{Materyal ve Metot}

Çalışmada değerlendirilen örnekler, Türkiye'nin Güneydoğu Anadolu Bölgesinde bulunan Adıyaman ve Gaziantep illerinden çukur tuzaklar vasitasıyla toplanmıştır (Şekil 1). Tür teşhisi Leica M125 marka stereomikroskop vasıtası ile yapılmıştır. Tanımlamada kullanılan vücut ölçümlerinde ve üreme organlarının kisımlarının isimlendirilmesi Chatzaki ve Arnedo (2006)'ya göre yapılmıştır. Metin içerisinde verilen tüm rakamsal birimler milimetre cinsindendir.

Kısaltmalar: AL, abdomen uzunluğu; CL, karapaks uzunluğu; CWmax, karapaksın maksimum genişliği; CWmin, karapaksın minimum genişliği; AME, anteriyör medyan gözler; PLE, posteriyör lateral gözler; PME, posteriyör medyan gözler; AMEd, anteriyör medyan gözlerin çapı; PLEd, posteriyör lateral gözlerin çapı; PMEd, posteriyör medyan gözlerin çapı; $\mathrm{ChF}$, keliseral fangin uzunluğu; ChG, keliseral oyuğun uzunluğu; ChL, keliserlerin toplam uzunluğu; Ta, tarsus; Me, metatarsus; Ti, tibia; Pa, patella; Fe, femur; Tr, trochanter; C, koksa; d, dorsal; pl, prolateral; $\mathrm{rl}$, retrolateral; $\mathrm{v}$, ventral.

\section{Bulgular}

Genus Harpactea Bristowe, 1939

Harpactea christodeltshevi Bayram, Kunt \& Yağmur, 2009 (Şekil 2-11)

H. christodeltshevi; Bayram, Kunt \& Yağmur (2009): 1, Şekiller 1-9 (Betimleme ô). 
S. hercegovinensis; Varol, 2016: 45, Sekiller 1A-B, 2A-B, 3AB (Betimleme ô, yanlış teşhis).

İncelenen örnekler: 10 ôิ人, 3 우, Gaziantep, Şehitkamil, Sofalıc köyü (37 7'36.00"K 37 5'30.00"D) asl c. 1200 m 23 Mart $\leftrightarrow 15$ Eylül 2016, leg. E. A. Yağmur; 9 숭, 5 우옹 Adıyaman, Gölbaşı, Kapıdere köyü yol ayrımı, 6 km kuzeyi (375' $\left.3^{\prime} 8.00^{\prime \prime K} 37^{\circ} 43^{\prime} 5.00^{\prime \prime D}\right)$, çukur tuzak, 06 Nisan $\leftrightarrow 21$ Ağustos 2017, leg. E. A. Yağmur; 10 ڤิô, 2 우, Adıyaman, Gerger, Gönen köyü, $3 \mathrm{~km}$ kuzeyi $\left(38^{\circ}\right.$ 3'44.00"K 39 6'28.00"D), 05 Nisan $2017 \leftrightarrow 3107$ 2018, leg.

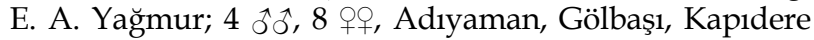
köyü yol ayrımı, 6 km kuzeyi (3753'8.00"K 37²43'5.00"D), 21 Ağustos $2017 \leftrightarrow 30$ Haziran 2018, leg. E. A. Yağmur; Adıyaman, Sincik, Subaşı köyü, 1 km güneyi (38 0'28.00"K 38²'32.00"D), 22 Ağustos $2017 \leftrightarrow 31$ Temmuz 2018, leg. E. A. Yağmur; 13 ôेิ, 1 ㅇ, Adryaman, Palanlı köyü (3750'4.00"K 38¹8'56.00"D), 22 Ağustos $2017 \leftrightarrow 31$ Temmuz 2018, leg. E. A. Yağmur.

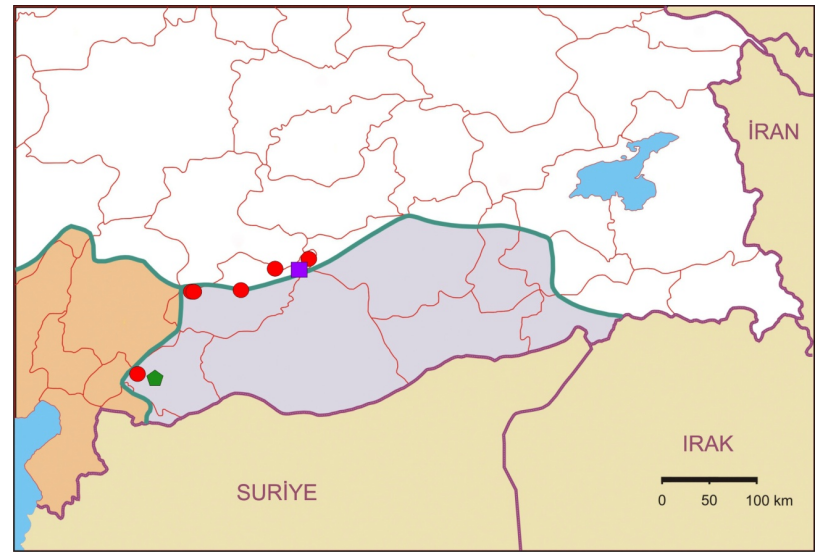

Şekil 1. Harpactea christodeltshevi'nin Güneydoğu Anadolu'daki dağılımı. Mor kare —: tip yeri; Yeşil beşgen • Varol (2016); Kırmızı noktalar : Örnek toplanan yeni yerler.

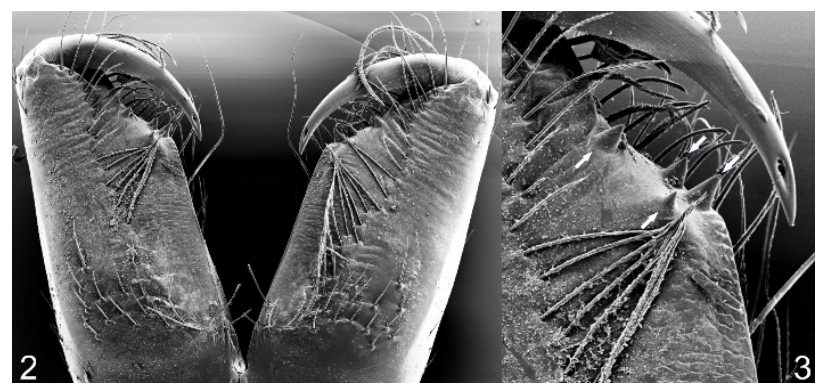

Şekil 2-3. Keliseral dişçikler. Şekil 3'de oklar dişçiklerin keliseral oyuktaki konumlarına işaret etmektedir.

Teşhis: Harpactea christodeltshevi tegulumunun yapısal özellikleri itibarıla $H$. martensi Dunin, $1991 \mathrm{H}$. mcheidzeae Dunin, 1992 ve H. spasskyi Dunin, 1992 türleri ile yakınlı göstermektedir. Bununla beraber $H$. christodeltshevi, $H$. martensi ve $H$. mcheidzeae'den kondüktörünün varlığı; $H$. spasskyi'den ise kondüktörünün basit, kısa ve dikensi oluşu sebebi ile kesin bir şekilde ayrılmaktadır. H. christodeltshevi'nin dişisinin farklılığ 1 ise bahsi geçen türlerin dişilerinden yine vulvar özelliklerinden dolayıdır. Şöyle ki, H. christodeltshevi'de anteriyör spermateka diğer türlerinkilere kıyasla son derece basittir. Distal krest ve spermatekanın distalinde yer alan genişlik birleşerek adeta bir küre görünümü kazanmıştır. $H$. christodeltshevi bu özelliği sebebi ile Yunanistan'dan bilinen Harpactea krueperi (Simon, 1884) ile yakınlık gösterse de, $H$. krueperi'de anteriyör spermatekanın bazal transvers kismı ve anteriyör bazal yay çok daha iyi gelişmiş ve ayrıca $H$. christodeltshevi'ninkilerden kesinlikle farklıdır (Bakınız: Le Peru (2011), sayfa 273, şekil, 418).

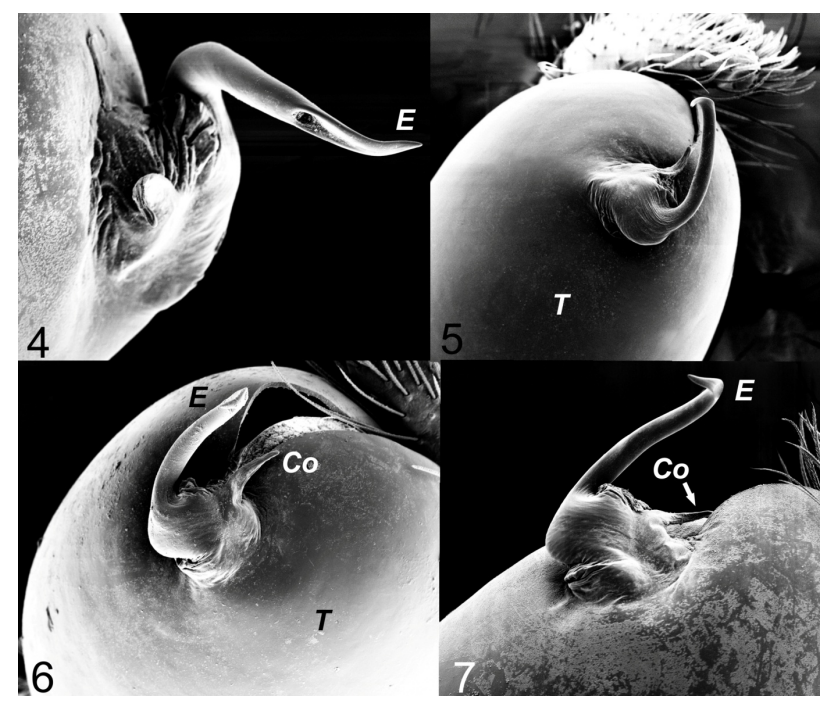

Şekil 4-7. Harpactea christodeltshevi, erkek üreme organına ait farklı açılardan çekilmiş SEM fotoğrafları $E$ embolus $C o$ kondüktör $T$ tegulum

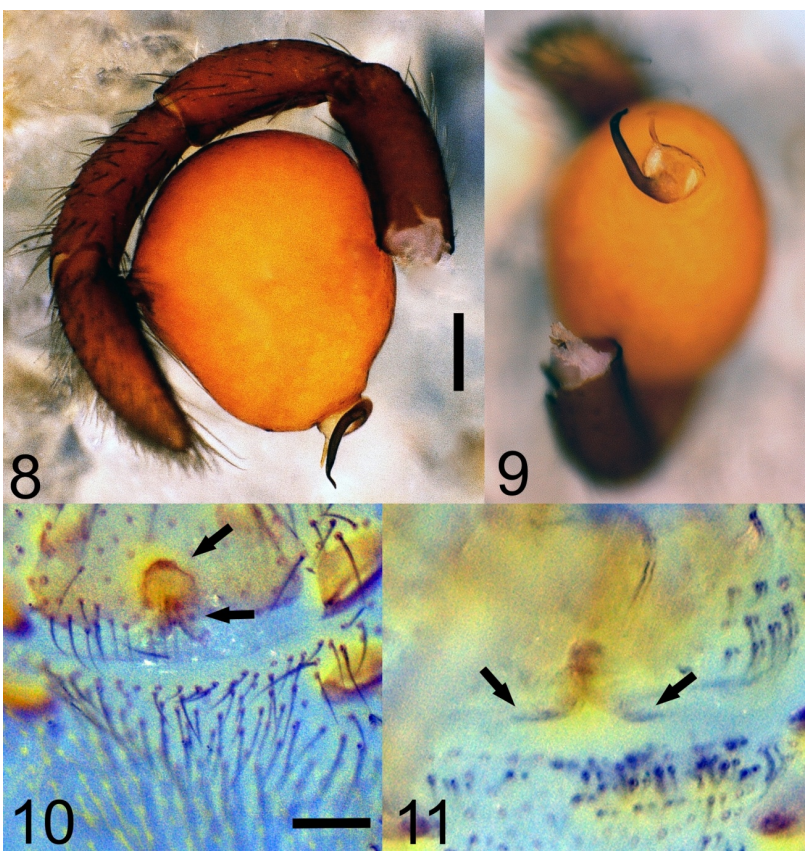

Şekil 8-11. Harpactea christodeltshevi. 8-9. Erkek üreme organına ait farklı açılardan çekilmiş stereomikroskop fotoğrafları. 10-11. Dişi üreme organı, dorsal görünüş. Şekil 10 'da üstteki ok küre görünümündeki yapıya; alttaki ok sklerotize halkaya; Sekil 11 'deki oklar ise anteriyör spermatekanın basal transvers kısmına dikkat çekmektedir. Ölçüm çizgileri: 8: 0.25, 10: 0.075

Vücut Ölçümleri (Erkek / Dişi): AL 1.70-1.80 / 2.302.34 CL 1.70-1.80 / 1.52-1.55 CWmax 1.18-1.30 / 1.15-1.20 CWmin 0.50-0.70 / 0.60-0.78 AMEd 0.06-0.08 / 0.06-0.07 PLEd 0.07-0.08 / 0.06-0.09 PMEd 0.07-0.08 / 0.07-0.08 ChF 0.30-0.41 / 0.28-0.36 ChG 0.14-0.18 / 0.12-0.20 ChL 0.27$0.38 / 0.14-0.44$

Betimleme: Küçük ya da orta boylu harpactein örümceklerdir. Karapaks açık kahverengi. Fovea mevcut, belirgin ve düz. AME, PLE ve PME halkasal sıralanmışlar. AME'ler arasında çok hafif bir açıklık bulunmaktadır. Sternum, gnathokoksalar ve labyum sarımsı kahverengi; sternumun yüzeyi siyahımsı ince ve kısa tüylerle kaplı; 
sternumun kenarında yer alan tüyler diğerlerine kıyasla daha uzun; keliserlerin ön yüzeylerinde siyahımsı, orta kısımlarından tüylerin çıktığı kabartılar bulunmakta; keliseral oyukta dört adet dişçik yer almaktadır.

Bacaklar karapaks ile aynı renkte, yüzeyleri siyahımsı ince tüycüklerle örtülü. Posteriyör yürüme bacaklarının tarsus ve metatarsuslarında zayıf olmakla beraber skopula bulunmakta. Sayıları bireyler arasında değişmekle birlikte 3 . patellalar ile 4 . koksalar diken taşımaktadırlar. Bacak formülü: 4123 nadiren 4213. Ayrıntılı bacak dikenlenmesi ve ölçümleri için bakınız Tablo 1-4. Abdomen grimsi, açık kahverengi.

Tablo 1. Harpactea christodeltshevi, Bacak dikenlenmesi, erkek

\begin{tabular}{|c|c|c|c|c|}
\hline Bacak & I & II & III & IV \\
\hline C & 0 & 0 & $0-1 \mathrm{rl}$ & $1 \mathrm{rl}$ \\
\hline $\mathrm{Fe}$ & $0-3 \mathrm{pl}$ & $1-2 \mathrm{pl}$ & $1-4 \mathrm{pl} \mathrm{0-2} \mathrm{d} \mathrm{0-2} \mathrm{rl}$ & $0-2 \mathrm{pl} \mathrm{0-2} \mathrm{rl} \mathrm{0-4} \mathrm{d}$ \\
\hline $\mathrm{Pa}$ & 0 & 0 & $1 \mathrm{pl}$ & 0 \\
\hline $\mathrm{Ti}$ & 0 & 0 & $3 \mathrm{pl} 2 \mathrm{rl} 4-5 \mathrm{v}$ & $3-4 \mathrm{pl} \mathrm{2-3} \mathrm{rl} \mathrm{4-5} \mathrm{v}$ \\
\hline $\mathrm{Me}$ & 0 & 0 & 2-3 pl 3-4 rl 3-4 v & $3-5 \mathrm{pl} 1-2 \mathrm{rl} 3 \mathrm{v}$ \\
\hline
\end{tabular}

Tablo 2. Harpactea christodeltshevi, Bacak dikenlenmesi, dişi

\begin{tabular}{|c|c|c|c|c|}
\hline Bacak & I & II & III & IV \\
\hline $\mathrm{C}$ & 0 & 0 & $2 \mathrm{rl}$ & $1 \mathrm{rl}$ \\
\hline $\mathrm{Fe}$ & $0-2 \mathrm{pl}$ & $2 \mathrm{pl}$ & 0 & $2 \mathrm{pl}$ \\
\hline $\mathrm{Pa}$ & 0 & 0 & $1-2 \mathrm{pl}$ & 0 \\
\hline $\mathrm{Ti}$ & 0 & 0 & $3 \mathrm{pl} \mathrm{0-3} \mathrm{rl} 4 \mathrm{v}$ & 3-4 pl 3 rl 4-5 v \\
\hline $\mathrm{Me}$ & 0 & 0 & $3 \mathrm{pl} 2-3 \mathrm{rl} \mathrm{3-4} \mathrm{v}$ & $3-5 \mathrm{pl} 2 \mathrm{rl} 3 \mathrm{v}$ \\
\hline
\end{tabular}

Tablo 3. Harpactea christodeltshevi, Bacak kısımlarının uzunlukları, erkek

\begin{tabular}{lcccccc}
\hline Bacak & C & Tr & Fe & Pa & Ti & Me \\
\hline I & $0.47 / 0.64$ & $0.11 / 0.16$ & $0.89 / 1.40$ & $0.82 / 0.84$ & $0.94 / 1.02$ & $0.76 / 0.94$ \\
II & $0.37 / 0.62$ & $0.08 / 0.14$ & $0.75 / 1.26$ & $0.69 / 0.70$ & $0.89 / 0.74$ & $0.40 / 0.98$ \\
III & $0.19 / 0.28$ & $0.13 / 0.14$ & $0.81 / 0.82$ & $0.42 / 0.54$ & $0.64 / 0.80$ & $0.64 / 0.88$ \\
IV & $0.37 / 0.38$ & $0.12 / 0.14$ & $0.97 / 1.40$ & $0.42 / 0.76$ & $0.96 / 1.20$ & $0.30 / 0.38$ \\
\hline
\end{tabular}

Tablo 4. Harpactea christodeltshevi, Bacak kısımlarının uzunlukları, dişi

\begin{tabular}{lccccccc}
\hline Bacak & C & Tr & Fe & Pa & Ti & Me \\
I & $0.48 / 0.56$ & $0.10 / 0.16$ & $0.88 / 1.12$ & $0.70 / 0.72$ & $1.04 / 0.86$ & $0.84 / 0.62$ \\
II & $0.38 / 0.50$ & $0.08 / 0.14$ & $1.04 / 1.06$ & $0.62 / 0.70$ & $0.84 / 1.00$ & $0.76 / 0.86$ \\
III & $0.24 / 0.32$ & $0.10 / 0.10$ & $0.60 / 0.94$ & $0.38 / 0.40$ & $0.40 / 0.70$ & $0.38 / 0.80$ & $0.32 / 0.38$ \\
IV & $0.28 / 0.44$ & $0.12 / 0.18$ & $1.32 / 1.44$ & $0.54 / 0.68$ & $1.04 / 1.20$ & $1.24 / 1.40$ & $0.40 / 0.44$ \\
\hline
\end{tabular}

Palp. Tegulum oval, şişkin. Embolus ve kondüktör tegulumun ucunda yer alan bir kaide kısmindan köken almakta. Embolus kuvvetlice sklerotize olmuş, siyah. Tabanda daha kalın, uca doğru hafifçe incelmekte; ucu kıvrık. Kondüktör tegulum ile aynı renkte, kısa ve dikensi; çıplak gözle çok zor anlaşılmakla birlikte hilalimsidir.

Vulva. Genel olarak zayıf sklerotize olmuş, maserasyon sonrasında bile belli belirsiz seçilmekte. Distal krest ve spermatekanın distalinde yer alan genişlik, muhtemelen birleşerek küre görünümünde bir yapıya dönüşmüştür. $\mathrm{Bu}$ yapının, spermatekanın çubuğumsu kısmı ile birleştiği noktada yüzük şeklinde sklerotize bir bölge seçilmektedir. Spermatekanın çubuğumsu kısmının uzunluğu küresel yapı ile yaklaşık olarak aynı olup bu kısım posteriyöre doğru ters V şeklinde ayrılarak anteriyör spermatekanın bazal transvers kısmını oluşturmaktadır.

Not. Harpactea christodeltshevi; küresele yakın oval tegulumu, masif embolusu, 3. patellaları ile 4. koksalarının taşıdığı dikenlerden dolayı Deeleman-Reinhold (1993) tarafından tesis edilen rubicunda (D) tür grubuna dâhildir. Dişi bireylerin vulvalarında posteriyör divertikulum gözlemlenememiştir. Muhtemelen çok küçük ve hassas olmalarından dolayı kesi esnasında zarar görmüşlerdir. Ancak dişi bireylerin bacak dikenlenmeleri, rubicunda (D) tür grubu ile uyum içerisindedir (Bakınız: Tablo 2).

\section{Tartışma}

Bayram, Kunt ve Yağmur (2009), Harpactea christodeltshevi'nin erkeğini betimledikleri makalelerinde erkek üreme organı kısımlarından embolusu kondüktör, kondüktörü ise embolus olarak yanlış vermişlerdir. $H$. christodeltshevi'nin erkek üreme organının distal uzantıları arasında "aksesuar apofiz" bulunmamaktadır. Oysa Bayram, Kunt ve Yağmur (2009), türün üreme organını betimlerken embolus ve kondüktörün köken aldığı geniş kaideyi "aksesuar apofiz" olarak değerlendirmişlerdir. Chatzaki ve Arnedo (2006), aksesuar apofizi şu şekilde tanımlamaktadırlar: "bazı türlerde görülebilen; embolus ve kondüktörün tersi istikametine yönelmiş apofiz". Bu tanım gereğince $H$. christodeltshevi'nin erkek üreme organında kesinlikle aksesuar apofiz yer almamaktadır. Metin içerisinde sunduğumuz SEM fotoğrafları da bunu ispatlar niteliktedir.

Bosna Hersek, Hirvatistan ve Güney Dalmaçya mağaralarında dağılım gösteren Stalagtia hercegovinensis (Nosek, 1905)'te genel olarak gözler tamamen ortadan kalkmıştır. Sadece istisnai olarak Bjelusica (Bosna-Hersek) ve Zaton (Hırvatistan) popülasyonlarında küçük gözlü bireylere rastlanmıştır (Deeleman-Reinhold, 1993). Bunun yanı sıra $S$. hercegovinensis'in her iki eşeyi de ön yürüme bacaklarında çok sayıda diken taşımaktadır ve erkek üreme organinda embolusun boyu teguluma hemen hemen eşittir. Teşhise yönelik olarak sıralanan bu özelliklerin hiç bir tanesi, Varol (2016) tarafından, S. hercegovinensis olarak Gaziantep'ten kaydedilen türde bulunmamaktadır. Dikkatli incelendiğinde, ilgili makalede, erkek üreme organı fotoğrafının $H$. christodeltshevi'ye ait olduğu görülmektedir (Bakınız: Varol (2016), sayfa 46, şekil 3B). Ayrıca Varol (2016)'nın örnekleme yerinin (Burç Ormanı, Şahinbey, Gaziantep) yakınındaki bir mesafeden (Sofalıcı Köyü), $H$. 
christodeltshevi örneklediğimiz için; bu, iddiamıza ikinci bir ispat niteliğindedir.

$\mathrm{Bu}$ çalışma ile daha önce sadece erkeği bilinen $H$. christodeltshevi'nin dişi bireyi de betimlenmiş; ilk betimlemede yapılan bazı teknik hatalar düzeltilmiş, eksiklikler giderilmiş ve sadece tip yerinden bilinen türün dağılım alanı nispeten genişletilmiştir. Bunlara ek olarak da S. hercegovinensis, Türkiye Örümcekleri tür listesinden düşürülmüştür.

\section{Kaynaklar}

Bayram, A., Kunt, K.B. \& Yağmur, E. A. (2009). A new spider species of the genus Harpactea (Araneae; Dysderidae) from southeast Anatolian region of Turkey. Turkish Journal of Arachnology, 2(2), 1-4.

Chatzaki, M., \& Arnedo, M.A. (2006). Taxonomic revision of the epigean representatives of the spider subfamily Harpacteinae (Araneae: Dysderidae) on the island of Crete. Zootaxa, 1169, 1-32.

Danışman, T., Kunt, K.B., \& Özkütük, R.S. (2019). The Checklist of the Spiders of Turkey. Retrieved from http:/ / www.spidersofturkey.info

Deeleman-Reinhold, C.L. (1993). The genus Rhode and the harpacteine genera Stalagtia, Folkia, Minotauria, and Kaemis (Araneae, Dysderidae) of Yugoslavia and Crete, with remarks on the genus Harpactea. Revue Arachnologique, 10, 105-135.

Kunt, K.B. (2019). Antalya ili Harpacteinae (Araneae, Dysderidae) faunast (Yüksek Lisans Tezi), Eskişehir Teknik Üniversitesi, Eskişehir, Türkiye.

Le Peru, B. (2011). The spiders of Europe, a synthesis of data: Volume 1 Atypidae to Theridiidae. Mémoires de la Société Linnéenne de Lyon, 2, 1522 .

Varol, M.İ. (2016). Stalagtia hercegovinensis (Nosek, 1905), a new record from Turkey (Araneae: Dysderidae). Serket, 15(1), 44-46.

World Spider Catalog (2019). Natural History Museum Bern. Retrieved from http://wsc.nmbe.ch. doi: 10.24436/2. 